Running Head: Bilingualism and reversal

\title{
Bilinguals' inhibitory control and attentional processes in a visual perceptual task
}

Marina C. Wimmer*1 ${ }^{*}$ Christina Marx², Steven Stirk ${ }^{1}$, and Peter J.B. Hancock ${ }^{3}$

1 University of Plymouth, School of Psychology, Cognition Institute, Plymouth, UK, PL4 $8 \mathrm{AA}$

2 University of Salzburg, Department of Psychology, 5020 Salzburg, Austria 3 University of Stirling, Psychology, Faculty of Natural Sciences, Stirling, UK, FK9 4LA

*Corresponding author information: School of Psychology, University of Plymouth, Plymouth, UK PL4 8AA, email: marina.wimmer@plymouth.ac.uk, phone: +44/(0)1752 585881, facsimile: $+44 /(0) 1752584808$.

Word Count $=4435$ (excluding abstract and reference list)

Submission date: June $6^{\text {th }} 2019$ 


\begin{abstract}
The aim was to examine theories of bilingual inhibitory control superiority in the visual domain. In an ambiguous figure task the ability to reverse (switch) interpretations (e.g., duckrabbit) was examined in 3-5-year-old bilinguals and monolinguals $(N=67)$. Bilingualism was no performance predictor in conceptual tasks (Droodle task, false belief task, ambiguous figures production task) that did not pose inhibitory demands. Bilinguals outperformed monolinguals in the ability to reverse, suggesting superior inhibitory capacity per se. Once reversal was experienced there was no difference in the time it took to reverse or reversal frequency between bilinguals and monolinguals. Bayesian analyses confirmed statistical result patterns. Findings support the established view of bilinguals' superior domain-general inhibitory control. This might be brought to bear by attending the environment differently.
\end{abstract}

Keywords: bilingualism; inhibition; ambiguous figures; reversal; attention; executive control 
Bilinguals face the challenge of selecting the context appropriate language in communication, which requires inhibiting the non-relevant language (Blumenfeld \& Marian, 2013). Bilingual children have been shown to have superior inhibitory control referring to both inhibition of prepotent responses and response conflict (Bialystok \& Martin, 2004; Carlson \& Meltzoff, 2008; Poarch \& van Hell, 2012) that is already evident at 4 years when inhibition develops (Bialystok, Barac, Blaye, Poulin-Durbois, 2010; Martin-Rhee \& Bialystok, 2008). There is theoretical debate about whether bilingual inhibitory control is a result of domain-general superiority (Green, 1998) or different attention to the environment that causes superior inhibitory control (Bialystok, 2015). Moreover, there is disagreement on the strength of the bilingual inhibitory control superiority effect (Lehtonen, Soveri, Laine, Järvenpää, de Bruin, \& Antfolk, 2018; Paap, Johnson, \& Sawi, 2015; Ross \& Melinger, 2016). The aim of the current research was to test these theories in children aged 4 and 5 years in a visual perceptual task that involves stimulus inhibition and attention and to further the debate on bilinguals' inhibitory control superiority.

The long-standing view is that bilinguals possess a domain-general inhibitory control mechanism (Green, 1998), the supervisory attentional system (SAS), that inhibits the nonrequired language to retrieve the situation-relevant language. The amount of inhibitory strength required is proportional to the activation strength of the irrelevant language (Green, 1998). Bilingual superior inhibitory control is evidenced in non-linguistic cognitive tasks requiring inhibition of prepotent responses and resolving response conflict (Bialystok et al., 2010; Carlson \& Meltzoff, 2008; Wimmer \& Marx, 2014). Specifically, 4- to 8-year-old and adult bilinguals are faster to respond in Simon tasks (press left key to a red square at right side of screen) and Flanker tasks (right facing stimulus is flanked by congruent or incongruent facing stimuli) than monolinguals (Bialystok, Martin \& Viswanathan, 2005; Costa, Hernández, Costa-Faidella, Sebastián-Gallés, 2009; Engel de Abreu, Cruz-Santos, 
Tourinho, Martin, \& Bialystok, 2012; Poarch \& van Hell, 2012), suggesting superior interference suppression. Bilingual 4-5-year-olds are also better able to switch interpretations of an ambiguous figure such as the duck/rabbit (Jastrow, 1900) that may underlie superior stimulus inhibition (Wimmer \& Marx, 2014). Thus, bilingual superiority is observed in visual perception and conflict resolution tasks between incongruent stimuli-response sets.

Alternatively, bilinguals' inhibitory control may be developed by the need to discriminate language information in their environment (Bialystok, 2015). Indeed, bilingual adults' high-level attention is less affected by irrelevant task demands (Hernández, Costa, \& Humphreys, 2012). Attentional level and bilingualism also interact in inhibitory task performance. When attentional level is high bilingualism has a larger effect on 8- and 11year-olds' Stop signal performance (do not respond when there is a stop signal such as a tone) compared to low attention (Sorge, Toplak, \& Bialystok, 2017). When attentional level is low then bilingualism has larger influence on accuracy in the Flanker task (but not on response time) (Sorge et al., 2017). Thus, the relative contribution of bilingualism under different attentional levels is dependent on the type of inhibition task.

However, superiority in inhibitory and attentional processes is not universally evident (Ross \& Melinger, 2016). First, bilinguals do not show superiority across measures of response inhibition such as the Stroop task (Duñabeitia et al., 2014; Martin-Rhee \& Bialystok, 2008 but see Esposito, Baker-Ward, \& Mueller, 2013 for Stroop superiority under interference suppression conditions). Second, recent studies report no bilingual advantage in 6- to 12-year-olds in the aforementioned Flanker (Antón, et al., 2014; Ladas, Carroll, \& Vivas, 2015; Ross \& Melinger, 2016) and Simon tasks (Morton \& Harper, 2007; Gathercole et al., 2014; Ross \& Melinger, 2016). These results cannot be accounted by socio-economic disadvantages in bilinguals (Ladas, et al., 2015). Only half of Simon and Flanker tasks show bilingual superiority (Ross \& Melinger, 2016; Hilchey, Saint-Aubin, \& Klein, 2015). Further, 
the effect may be on overall reaction time (Engel de Abreu et al., 2012; Martin-Rhee \& Bialystok, 2008; Morales, Calvo, \& Bialystok, 2013) rather than in incongruent trials requiring inhibitory control (Morales, et al., 2013; Poarch \& Van Hell, 2012). Additionally, recent null results may indicate previous publication bias (Lehtonen et al., 2018; Paap, et al., 2015; Ross \& Melinger, 2016), raising doubts about the strength of the effect.

On the other hand research on ambiguous figure perception has consistently shown bilingual superiority (Bialystok \& Shapero, 2005; Chung-Fat-Yim, Sorge, \& Bialystok, 2017; Wimmer \& Marx, 2014). Three to 5-year-old bilinguals more likely perceive both interpretations of an ambiguous figure (reverse) than monolinguals when informed about the two interpretations ("this can be a duck and a rabbit") (Wimmer \& Marx, 2014). When naïve about the two interpretations but aware of ambiguity, 6-year-old bilinguals require fewer prompts or support of an unbiased version to identify features of the alternative interpretation (Bialystok \& Shapero, 2005). When one interpretation (e.g., duck) gradually morphs into the alternative interpretation (i.e., rabbit), adult bilinguals require fewer frames to guess the alternative interpretation (Chung-Fat-Yim et al., 2017).

This consistent superiority pattern in ambiguous figure perception is surprising given the different task demands and different populations (adults versus children). Specifically, Wimmer and Marx's (2014) findings reveal bilingual superior inhibitory ability in reversal as the task has been adapted from previous research demonstrating that the ability to reverse per se requires inhibitory processes (Doherty \& Wimmer, 2005; Wimmer \& Doherty, 2011). Moreover, the stimuli themselves remained unchanged and children were informed of alternative interpretations. Thus, they knew what to inhibit. Attention does not seem to play a role in the ability to reverse per se as 3- to 5-year-olds'stimulus fixation patterns do not differ between reversers and non-reversers (Wimmer \& Doherty, 2007). In contrast, other findings of a bilingual advantage may reflect attentional processes (Bialystok \& Shapero, 2005; 
Chung-Fat-Yim et al., 2017). In these tasks, the stimulus changed either directly by morphing from one interpretation to the other or by scaffolding features in prompts and adding biased interpretations to perceive the alternative interpretation. This may require attentional disengagement from the prevalent stimulus properties (Chung-Fat-Yim, et al., 2017) but as attentional level has not been manipulated this claim is difficult to verify.

Given the current debate, the aim was to implement the ambiguous figures task that has shown superiority in bilinguals' ability to reverse per se requiring stimulus inhibition (Wimmer, \& Doherty, 2011). Moreover, the role of attention in ambiguous figure perception was examined further by measuring the time to first reversal and the number of reversals as stimulus attention and reversal rate are related (Alais, van Boxtel, Parker, \& van Ee, 2010; Meng \& Tong, 2004; Intaite, Kovisto, Castelo-Branco, 2014). Higher attention can lead to both faster first reversal and higher reversal rate (Intaite et al., 2014). Increased attention may also reduce reversal rate due to increasing the prevalence of a perceived interpretation (Scocchia, Valsecchi, \& Triesch, 2014). Bilinguals may show different reversal rates and/or time to first reversal than monolinguals if there is an interplay between attentional processing and bilingualism.

Furthermore, research with ambiguous figures to date has so far revealed no bilingual superiority in the ability to acknowledge two interpretations (ambiguous figure production task, Wimmer \& Marx, 2014) that develops between 3- and 4 years and is a precursor for reversal (Doherty \& Wimmer, 2005; Wimmer \& Doherty, 2010). The ambiguous figure production task does not involve inhibitory control as it is related to mental and linguistic metarepresentation tasks that vary in their inhibitory control demands but underlie the same representational difficulties (Beck, Robinson, Ahmed, \& Abid, 2011; Wimmer \& Doherty, 2011). Indeed, there is no evidence of bilingual superiority in related conceptual developments in understanding ambiguity for another person (Droodle task, Chandler \& 
Helm, 1984) or mental metarepresentational understanding (understanding false beliefs, false belief task, Wimmer \& Perner, 1983) (Goetz, 2003; Wimmer \& Marx, 2014; but see Kovács, 2009 for superior false belief performance in 3-year-old bilinguals). To further examine bilingual performance in related conceptual tasks, the Droodle task, ambiguous figure production task, and false belief task were administered. Based on previous findings (Wimmer \& Marx, 2014) if the bilingual advantage in the ability to reverse per se is due to stimulus inhibition then no difference in mono- and bilinguals' conceptual development should emerge.

Together, the bilingual advantage reported in different ambiguous figures tasks may underlie superior inhibitory ability (Wimmer \& Marx, 2014) and attending to relevant stimulus information (Bialystok \& Shapero, 2005; Chung-Fat-Yim, et al., 2017). In light of current theoretical debate (Bialystok, 2015; Green, 1998) and the strength of the inhibitory superiority effect (Ross \& Melinger, 2016), the ability to reverse per se, the time to first reversal and the reversal rate were examined in 3-4- and 5-year old mono- and bilinguals. If general inhibitory control drives the bilingual advantage (Green, 1989) then bilinguals should be more able to reverse than monolinguals. This finding would be expected based on previous results (Wimmer \& Marx, 2014) but it is important to establish the strength of the effect based on recent null findings in inhibitory control (Ross \& Melinger, 2016). Additionally, it is asked what role attentional processes play. If bilinguals have superior attentional processing (Bialystok, 2015) then bilinguals should have a different time to first reversal and reversal rate. No difference in mono- and bilinguals' conceptual development that does not underlie inhibition should emerge.

\section{Method}

\section{Participants}

Overall 67 children, 34 monolinguals (47\% males) and 33 bilinguals (61\% males) from 
nursery and primary schools in south UK took part. The sample size was based on the bilinguals available at the time of testing. Socio-economic backgrounds ranged from deprived ( $4^{\text {th }}$ decile away from most deprived $)$ to not very deprived areas $\left(8^{\text {th }}\right.$ decile away from most deprived) according to the multiple deprivation index (Department for Communities and Local Government, 2015). Children were divided into two age groups, a nursery and primary school sample; monolinguals: 18 3-4-year-olds $(M=3.10, S D=4$ months), 16 5-year-olds ( $M=5.5, S D=3$ months); bilinguals: 15 3-4year-olds $(M=4.2, S D=7$ months), 18 5-yearolds $(M=5.6, S D=5$ months). The nursery sample (3-4-year-olds) comprised mono- and bilinguals who both attended two nurseries in neighbouring areas in Plymouth, UK with a relatively high deprivation index $\left(4^{\text {th }}\right.$ decile away from most deprived). The primary sample (5-year-olds) was recruited from two primary schools in neighbouring catchment areas in Brighton, UK, a less deprived part of the country ( $8^{\text {th }}$ decile away from most deprived). Thus, the socio-economic range was between age groups as opposed to between mono- and bilinguals. Both language groups were comparable in receptive vocabulary (3-4-year-olds: $t(31)=.30, p=.77$, two-tailed; 5-year-olds: $t(32)=.25, p=.81)$, indexed by the BritishPicture-Vocabulary Scale (BPVS-III) (Dunn et al., 2007).

Monolinguals were English native speakers. The inclusion criterion to be counted as bilingual was age of second language acquisition from birth. The bilinguals who attended nursery spoke English in school and another language at home daily constantly with at least one caregiver who was non-English native speaker. The bilinguals who attended primary school spoke both English and Spanish in school and at home daily constantly with at least one caregiver who was non-English native speaker. Native languages included Spanish (61\%), Kurdish (15\%), Bengali (6\%), Farsi (3\%), Slovakian (3\%), Romanian (3\%), Polish (3\%) Arabic (3\%), and Chinese (3\%). This research project "Bilinguals' understanding of pictures" was approved by the Health and Human Sciences Ethics Faculty board, University 
of Plymouth.

\section{Design}

Children received four tasks: ambiguous figures (AF) Production task, AF Reversal task, False Belief task and Droodle tasks, in counterbalanced order across participants. The BPVS-III was always administered in the end.

\section{Materials and Procedure}

Ambiguous figure (AF) production and reversal tasks. Three ambiguous figures (rabbit/duck $10 \mathrm{~cm} \times 6 \mathrm{~cm}$, man/mouse $4 \mathrm{~cm} \times 3.5 \mathrm{~cm}$ and seal/donkey $6 \mathrm{~cm} \times 8 \mathrm{~cm}$ ) and according interpretations were used (see Wimmer \& Doherty, 2011). Both tasks ran on a 15 inch laptop PC. Children sat approximately $50 \mathrm{~cm}$ from the screen.

The disambiguation phase was first, followed by the AF production and reversal phases. This was repeated for each AF.

In disambiguation children saw the AF (e.g., man/mouse) and were asked, "What is this?" After the child's response, (e.g.) "A mouse”, the corresponding disambiguating mouse content appeared left and right of the ambiguous figure (picture of mousehole and cheese), ("Yes, you are right, it is a mouse."). The child had to point to a specific feature (e.g., mouse's tail). Then, the alternative interpretation was introduced, by adding the disambiguating man context (man's body) ("But look it can be something else too, what is it now? ... Yes, you are right, it's a man.”). Children had to point out a specific feature (e.g., man's nose). It was crucial that children perceived and reported the alternative interpretation during disambiguation. When a child failed to point to the specific feature, the experimenter would point out other features of this interpretation (e.g., head, body), before the child pointed out features again. At this stage all children were able to indicate features of the alternative interpretation. Then the disambiguating context was removed and the experimenter said: "So this picture can be two different things, it can be a man and a mouse." 
The production phase followed immediately. "Now we play a game. I am going to say one thing, and I want you to say the other thing, okay? What's this?" (to examine whether the child has changed interpretation). After the child's answer (e.g., "a mouse") the experimenter repeated the child's label by asking the $A F$ production test-question, "I say it's a mouse, what else can it be?" The task was to produce the alternative interpretation (i.e., "man"). If the child repeated the experimenter's label she would say, "Well I have already said that it's a mouse, what else can it be?" If the child still repeated the experimenter's label the alternative was produced for them: "I know, it can be a man, can't it?" Children who produced the alternative interpretation passed production (scores ranged from 0-3 alternatives of ambiguous figures produced).

Immediately after producing the alternative interpretation the reversal task followed. The experimenter showed the same ambiguous stimulus (e.g., man/mouse) and said: "Now I want you to keep looking at the picture and tell me what it is, because it might change or it might not change." The stimulus was then presented continuously for 60 seconds. Children were asked "what is it now?" after 0 seconds (immediately when the figure is shown), 30 and 60 seconds from stimulus onset and children responded during each time point. Children who reported a change in interpretation of the ambiguous figure at 0,30 , or 60 seconds were in the end asked to indicate features of their according interpretation to control for false positives. If they reported the alternative interpretation and indicated features they were coded as reversers. Children who did not report any change during 60 seconds were in the end asked to indicate features of the non-reported alternative interpretation to control for false negatives. If they were unable to indicate features they were deemed non-reversers. Three dependent variables were coded. Children scored from 0 to 3 ambiguous figures reversed (ability to reverse). Time to first reversal recorded when children first reported a different interpretation from their original one, either at 0,30 , or 60 seconds. How often children reversed was also 
recorded, a maximum of three per figure as they have been asked at three time points, at 0 , 30, 60 seconds, (number of reversals, range 0-9).

False belief task. The experimenter acted out a story with two play people dolls Tony and Sally, a yellow box, a black jewel case and a marble. Tony hid his marble in the box and went outside to play. Sally opened the box, took the marble, moved it to the case, and left too. Tony returned and the three test-questions were asked.

Belief question: "Where will Tony first look for the marble?"

Reality question: "Where is the marble really?"

Memory question: "Where did Tony put the marble in the beginning?"

Children passed if they answered all questions correctly.

Droodle task. Two pictures $(29.7 \mathrm{~cm}$ x $21 \mathrm{~cm})$ of a flower and an elephant were used. Each picture was covered with a white, non-transparent paper, with a cut-out $\left(3 \mathrm{~cm}^{2}\right)$ revealing an unidentifiable part of the picture ("Droodle").

Children were shown the Droodle and asked what it was. After the child's incorrect guess the full drawing was revealed. The drawing was covered again, showing the window. A doll called Sandy appeared and the child was asked the test question: "Sandy has never seen this picture before. If she comes in and sees just this bit, will she know that this is a flower/an elephant?" (Correct answer: "No"). In a control condition, the other drawing was fully visible from the start, and the children were asked the same test question (Correct answer: "Yes"). Children passed if they answered both questions correctly.

\section{Results}

Performance summary of all tasks for monolinguals and bilinguals is presented in table 1 . Because of power concerns (GPower, Faul, Erdfelder, Lang, \& Buchner, 2007) data were also analysed with the Bayesian approach determining the odds of whether the null or alternative hypotheses should be favoured. Effect size analysis is reported separately. 


\section{Task performances}

Ambiguous figure production task. The effect of age and language group on the mean number of alternative interpretations produced were examined in a univariate ANOVA. Five-year-olds $(M=92)$ produced more interpretations than $3-4$-year-olds $(M=44), F(1$, $63)=45.40, p<.001, \eta_{p}{ }^{2}=.42$. Bilinguals $(M=.78)$ produced more interpretations than monolinguals $(M=.60), F(1,63)=4.52, p=.04, \eta_{p}{ }^{2}=.07$. There was no interaction, $F(1,63)$ $=2.02, p=.16, \eta_{p}^{2}=.03$.

The ANOVA suggests a weak effect of bilingualism on production performance. To further assess the evidence, we calculated the Bayes factor, using a JZS prior (Rouder, Speckman, Sun, Morey, \& Iverson, 2009). The odds, BF=1.11, are very close to 1, meaning that there is no useful evidence either for or against the null hypothesis.

Ambiguous figure reversal task. For the analysis on whether an ambiguous figure was reversed, trials were included only if the according alternative interpretation had been produced beforehand. This included 68\% of trials (137 trials out of 201). However the same results were obtained if all trials were included. A univariate ANOVA on mean number of figures reversed in mono- and bilinguals and across both age groups, showed that 5-year-olds $(M=46)$ reversed more ambiguous figures than 3-4-year-olds $(M=.11), F(1,54)=17.61, p$ $<.001, \eta_{p}{ }^{2}=.25$. Additionally, bilinguals $(M=.45)$ reversed more figures than monolinguals $(M=.18), F(1,58)=10.14, p=.002, \eta_{p}^{2}=.16$. There was no interaction, $F(1,54)=.02, p=$ $.90, \eta_{p}^{2}=.001$

As above, the JZS Bayes factor was obtained. The odds are in favour of the alternative hypothesis, $\mathrm{BF}=13.22$. A Bayes Factor larger than 10 is considered as strong evidence (Jeffries, 1961).

Furthermore, once mono- and bilingual children reversed, the number of reversals (range 1-9) did not differ between mono- $(M=3.85)$ and bilinguals $(M=4.3), t(31)=.75, p=$ 
.46. Bayesian analysis confirmed that the odds are in favour of the null hypothesis, $\mathrm{BF}=$ 4.18.

Additionally, the data on time of first reversal indicated that, for trials where a reversal was observed, it was very likely to occur within the first 30 seconds; on $90 \%$ of trials for bilinguals and $72 \%$ for monolinguals. Due to low numbers involved, the difference is not meaningful. Comparing the mode of first reversal time across the three figures for each participant who reversed $(N=33)$ shows that the frequency distribution is not different in mono- and bilinguals, Likelihood Ratio $=5.82, p=.055$ (Figure 1).

False belief task. Five-year-old children performed better than 3-4-year-olds ( $U=$ $268, p<.001$, Mann-Whitney). There was no difference between the two language groups (Mann-Whitney, $p=.90)$ (Table 1).

Droodle task. Similarly, children's performance increased with age $(U=232, p<$ .001 , Mann-Whitney) and there was no difference in language groups (Mann-Whitney, $p=$ .55) (Table 1).

\section{Process predictors}

To investigate the relation between false belief, Droodle tasks, chronological age, verbal mental age (BPVS-III score) and language group on production and the ability to reverse, two linear regressions with backward elimination method were conducted (Tables 2 and 3).

For both production and reversal, the models were significant, $R^{2}=.60, F(3,66)=$ $30.77, p<.001, R^{2}=.40, F(2,57)=17.22, p<.001$, respectively. For production, age and for reversal, both age and language group were the best predictors (Tables 2 and 3).

\section{Effect size: comparison between mono- and bilinguals}

Table 4 shows averages for each language group for age, BPVS score and success on the Droodle and False Belief tasks. It can be seen that in each case, the average for the bilingual group is higher than for the monolinguals. Since they differ in average age, we partialed out 
the effects of age on other variables, using linear regressions. We then used bootstrap resampling to estimate standardised effect sizes, with $95 \%$ confidence intervals, based on 5000 samples. The last lines in the table shows the difference between the two groups after controlling for age; in each case the $95 \%$ CI include zero, with small effect sizes, indicating no reliable difference between the groups.

Table 5 shows averages for ambiguous figure production, number of figures reversed and total number of reversals. It is apparent that, even after controlling for age, there is a meaningful difference in the number of figures reversed between the two language groups. Figure 2 shows standardised effect sizes for the three differences, with 95\% CI. There is a reliable, medium effect size for number of figures reversed.

\section{Discussion}

This research was motivated by the theoretical question of whether bilingual children's superiority in inhibitory control is domain general (Green, 1998). It also investigated the role of attention in bilingual superiority (Bialystok, 2015). Using an ambiguous figures perception task, bilingual 3-4- to 5-year-olds were more likely to reverse ambiguous figures. This finding replicates earlier research that used similar methodology and asked to indicate features ("can you point the beak of the duck?") measuring reversal (Wimmer \& Marx, 2014) rather than to report their percept (“what is it now?") (current study). Bilingual superiority is also in line with evidence of older children where 6-year-old bilinguals require fewer prompts to identify the alternative interpretation when naïve about the interpretations (Bialystok \& Shapero, 2005) and adult bilinguals who require fewer frames to indicate a change in percept morphing from one disambiguating interpretation to the other (Chung-Fat-Yim et al., 2017). Consistent finding of bilingual superiority is striking given the different methodologies and age groups involved. Moreover, the current task adapted previous paradigms that have shown that the ability to reverse is predicted by 
response inhibition (Wimmer \& Doherty, 2011). Thus, in the current paradigm, response inhibition may drive the ability to reverse and provide support for the traditional general inhibitory control account (Green, 1998).

We replicated earlier findings of no conceptual differences between the groups on the Droodle task, false belief task, and production task (Goetz, 2003; Wimmer \& Marx, 2014). To date only one study shows superior false belief performance in bilingual 3-year-olds (Kovács, 2009), thus it is unclear how robust this finding is. Together, findings support the notion of a bilingual advantage in stimulus inhibition per se as opposed to it underlying conceptual developments (Green, 1998; Wimmer \& Marx, 2014). One possibility is that the bilingual advantage rests in "stimulus-stimulus" specific inhibitory control advantage akin to their dual language use rather than a "stimulus-interference" advantage (Blumenfeld \& Marian, 2014).

The question is whether attention also has a role in bilinguals' performance. Both the time to first reversal and reversal rate are linearly related to attentional level (Intaite, et al., 2014). Both our bilinguals' first reversal and reversal rate were not different to monolinguals'. However, stimulus attention may still have brought inhibition to bear (Bialystok, 2015) allowing reversal per se. Future research should directly manipulate attentional level during ambiguous figure perception examining the directionality of the relation of bilingualism and attention.

However, the lack of difference in reversal rate ties in nicely with null results in Flanker, Simon and Stroop tasks, where inhibitory control is applied on a trial by trial basis across trials (Duñabeitia et al., 2014; Gathercole et al., 2014; Ladas et al., 2015), including developmental studies that have large sample sizes (Ross \& Melinger, 2016). Our sample size is modest but the Bayesian analysis and previous work (Wimmer \& Marx, 2014) indicates 
strong support for an effect on reversal, so perhaps this is one of the specific tasks where inhibition does have an effect (Ross \& Melinger, 2016).

How can the current bilingual advantage then be best explained? Our bilinguals were comparable to the monolinguals in their verbal mental age and the regression findings indicate no role of verbal mental age in performance. Therefore, differences are unlikely to be accounted for by verbal mental age variations. However, a limitation is that no additional data on parental education and income were obtained as direct measures of socio-economic status (SES) for our sample. Previous findings suggest no link between various SES measures and ambiguous figures perception (Chung-Fat-Yim et al., 2017) but a general relation between SES and cognitive performance (Gathercole, et al., 2010). As such we cannot rule out the possibility that the groups differed in these SES measures linked to cognitive performance. A plausible explanation of positive findings may be that the bilingual advantage is particularly evident when abilities develop, giving them an advantage due to enhanced attention to their environment (Bialystok, 2015). Note that what was primarily measured here was the emerging ability to perceive both interpretations of an ambiguous figure that develops between 4- and 5 years of age. Indeed, the bilingual advantage is best observed early in development where studies that use younger children (Bialystok et al., 2005; MartinRhee \& Bialystok, 2008; Morales et al., 2013) are more likely to report an advantage than studies that used older children (Gathercole et al., 2014; Poarch \& Van Hell, 2012; Morton \& Harper, 2007). Moreover, this developmental effect seems to be task specific to Simon and set-shifting tasks (DCCS) (Bialystok \& Martin, 2004; Carlson \& Meltzoff, 2008) but not to the Flanker task (Ross \& Melinger, 2016). This highlights the importance of task difficulty in addition to the investigated age range (Costa et al., 2009). Thus, current findings may provide specific evidence for a bilingual advantage when inhibitory ability develops and the task is at optimum task difficulty for the age range under investigation. 
Findings contribute to recent debate in that bilingualism confers an advantage in the ability to reverse ambiguous figures, and stimulus inhibition and different attention to the environment may bring this advantage to bear. If so, then any task that reflects the development of stimulus inhibition, is at optimum task difficulty for the examined age range, and comprises a balanced sample in verbal mental age may elicit a bilingual advantage. 


\section{Compliance with Ethical Standards:}

Conflict of Interest: Marina C. Wimmer declares that she has no conflict of interest.

Christina Marx declares that she has no conflict of interest. Steven Stirk declares that he is no conflict of interest. Peter Hancock declares that he has no conflict of interest.

Ethical approval: All procedures performed in the study were in accordance with the ethical standards of the Plymouth University, Faculty of Health and Human Science ethics board and with the 1964 Helsinki declaration and its later amendments or comparable ethical standards.

Informed consent: Informed consent was obtained from all individual participants included in the study. 


\section{References}

Alais, D., van Boxtel, J. J., Parker, A., van Ee, R. (2010). Attending to auditory signals slows visual alternations in binocular rivalry. Vision Research, 50, 929-935. doi: 10.1016/j.visres.2010.03.010

Antón, E., Duñabeitia, J. A., Estévez, A., Hernández, J. A., Castillo, A., Fuentes, L. J., Davidson, D. J., \& Carreiras, M. (2014). Is there a bilingual advantage in the ANT task? Evidence from children. Frontiers in Psychology, 5, 398. doi: 10.3389/fpsyg.2014.00398

Beck, S. R., Robinson, A. N., Ahmed, S., \& Abid, R. (2011). Children's understanding that ambiguous figures have multiple interpretations. European Journal of Developmental Psychology, 8, 403-422. doi: 10.1080/17405629.2010.515885

Bialystok, E. (2015). Bilingualism and the development of executive function: The role of attention. Child Development Perspectives, 9, 117-121. doi: 10.1111/cdep.12116

Bialystok, E., \& Martin, M. M. (2004). Attention and inhibition in bilingual children: Evidence from the dimensional change card sort task. Developmental Science, 7, 325-339. doi: 10.1111/j.1467-7687.2004.00351.x

Bialystok, E., Martin, M. M., \& Viswanathan, M. (2005). Bilingualism across the lifespan: The rise and fall of inhibitory control. International Journal of Bilingualism, 9, 103 119.

Bialystok, E., Barac, R., Blaye, A., Poulin-Dubois, D. (2010). Word mapping and executive functioning in young monolingual and bilingual children. Journal of Cognition and Development, 11, 485-508. doi: 10.1080/15248372.2010.516420

Bialystok, E., \& Shapero, D. (2005). Ambiguous benefits: The effect of bilingualism on reversing ambiguous figures. Developmental Science, 8, 595-604. doi: 10.1111/j.1467-7687.2005.00451.x 
Blumenfeld, H. K., \& Marian, V. (2013). Parallel language activation and cognitive control during spoken word recognition in bilinguals. Journal of Cognitive Psychology, 25, 547-567. doi: 10.1080/20445911.2013.812093

Blumenfeld, H. K., \& Marina, V. (2014). Cognitive control in bilinguals: Advantages in stimulus-stimulus inhibition. Bilingualism: Language and Cognition, 17, 610-629. doi: $10.1017 / \mathrm{S} 1366728913000564$

Carlson, S. M., \& Meltzoff, A. M. (2008). Bilingual experience and executive functioning in young children. Developmental Science, 11, 282-298. doi: 10.1111/j.1467 7687.2008.00675.x

Carlson, S. M., \& Moses, L. J. (2001). Individual differences in inhibitory control and children's theory of mind. Child Development, 72, 1032-1053. doi: 10.1111/1467 8624.00333

Chandler, M. J., \& Helm, D. (1984). Developmental changes in the contribution of shared experience to social role-taking competence. International Journal of Behavioural Development, 7, 145-156.

Chung-Fat-Yim, A., Sorge, G. B., \& Bialystok, E. (2017). The relationship between bilingualism and selective attention in young adults: Evidence from an ambiguous figures task. The Quaterly Journal of Experimental Psychology, 70, 366-372. doi: $10.1080 / 17470218.2016 .1221435$

Costa, A., Hernández, M., Costa-Faidella, J., Sebastián-Gallés, N. (2009). On the bilingual advantage in conflict processing: Now you see it, now you don't. Cognition, 113, 135-149. .doi: 10.1016/j.cognition.2009.08.001

Doherty, M. J., \& Wimmer, M. C. (2005). Children's understanding of ambiguous figures: Which cognitive developments are necessary to experience reversal? Cognitive Development, 20, 407-421. doi: 10.1016/j.cogdev.2005.05.003 
Duñbeitia, J. A., Hernández, J. A., Antón, E., Macizo, P., Estévez, A., Fuentes, L. J., \& Carreiras, M. (2014). The inhibitory advantage in bilingual children revisited. Experimental Psychology, 61, 234-251. doi: 10.1027/1618-3169/a000243

Engel de Abreu, P. M. J., Cruz-Santos, A., Tourinho, C. J., Martin, R., Bialystok, E. (2012) Bilingualism enriches the poor: Enhanced cognitive control in low-income minority children. Psychological Science. 23, 1364-1371. doi: 10.1177/0956797612443836

Esposito, A., G., Baker-Ward, L., \& Mueller, S. (2013). Interference suppression vs. response inhibition: An explanation for the absence of a bilingual advantage in preschoolers' Stroop task performance. Cognitive Development, 28, 354-363. doi:10.1016\%2Fj.cogdev.2013.09.002

Faul, F., Erdfelder, E., Lang, A.-G., \& Buchner, A. (2007). G*Power 3: A flexible statistical power analysis program for the social, behavioral, and biomedical sciences. Behavior Research Methods, 39, 175-191. doi:10.3758/BF03193146

Gathercole, V. C. M., Thomas, E. M., Jones, L., Guash, N. V., Young, N., \& Hughes, E. K. (2010). Cognitive effects of bilingualism: digging deeper for the contributions of language dominance, linguistic knowledge, socio-economic status and cognitive abilities. Journal of Bilingual Education and Bilingualism, 13, 617-664. doi: $10.1080 / 13670050.2010 .488289$

Gathercole, V. C. M., Thomas, E. M., Kennedy, I., Prys, C., Young, N., Guasch, N. V., Roberts, E. J., Hughes, E. K., \& Jones, L. (2014). Does language dominance affect cognitive performance in bilinguals? Lifespan evidence from pre-schoolers through older adults on card sorting, Simon, and metalinguistic tasks. Frontiers in Psychology, 5, 11. doi: 10.3389/fpsyg.2014.00011

Goetz, P. J. (2003). The effect of bilingualism on theory of mind development. Bilingualism: Language and Cognition, 6, 1-15. doi:10.1017/S1366728903001007 
Gopnik, A., \& Rosati, A. (2001). Duck or rabbit? Reversing ambiguous figures and understanding ambiguous representation. Developmental Science, 4, 175-183. doi: $10.1111 / 1467-7687.00163$

Green, D. W. (1998). Mental control of the bilingual lexico-semantic system. Bilingualism: Language and Cognition, 1, 67-81. doi: 10.1017/S1366728998000133

Hernández, M., Costa, A., \& Humphreys, G. W. (2012). Escaping capture: Bilingualism modulates distraction from working memory. Cognition, 122, 37-50. doi: 10.1016/j.cognition.2011.08.002

Hilchey, M. D., Saint-Aubin, J., \& Klein, R. M. (2015). Does bilingual exercise enhance cognitive fitness in traditional non-linguistic executive processing tasks? In J. Schwieter (Ed.) The Cambridge Handbook of Bilingual Processing (pp. 586-613). Cambridge: Cambridge University Press. doi.org/10.1017/CBO9781107447257.026

Intaité, M., Koivisto, M., \& Castelo-Branco, M. (2014). Event-related potential responses to perceptual reversals are modulated by working memory load. Neuropsychologia, 56, 428-43. doi: 10.1016/j.neuropsychologia.2014.02.016

Jastrow, J. (1900). Fact and fable in psychology. Oxford, England: Houghton, Mifflin. Jeffreys, H. (1961). Theory of probability (3rd ed.). Oxford: Oxford University Press, Clarendon Press.

Ladas, A. I., Carroll, D. J., Vivas, A. B. (2015). Attentional processes in low-socioeconomic status bilingual children: Are they modulated by the amount of bilingual experience? Child Development, 86, 557-578. doi: 10.1111/cdev.12332

Lehtonen, M., Soveri, A., Laine, A., Järvenpää, J., de Bruin, A., \& Antfolk, J. (2018). Is bilingualism associated with enhanced executive functioning in adults? A meta analytic review. Psychological Bulletin, 144, 394-425. doi:10.1037/bul0000142

Martin-Rhee, M. M., \& Bialystok, E. (2008). The development of two types of inhibitory 
control in monolingual and bilingual children. Bilingualism: Language and Cognition, 11, 81-93. doi:10.1017/S1366728907003227

Meng, M., \& Tong, F. (2004). Can attention selectively bias bistable perception? Differences between binocular rivalry and ambiguous figures. Journal of_Vision, 4, 539-551. doi:10.1167/4.7.2

Morales, J., Calvo, A., \& Bialystok, E. (2013). Working memory development in monolingual and bilingual children. Journal of Experimental Child Psychology, 114, 187-202. doi: 10.1016/j.jecp.2012.09.002

Morton, B. J., \& Harper, S. N. (2007). What did Simon say? Revisiting the bilingual advantage. Developmental Science, 10, 719-726. doi: 10.1111/j.1467 7687.2007.00623.x

Paap, K. R., Johnson, H. A., \& Sawi, O. (2015). Bilingual advantages in executive functioning either do not exist or are restricted to very specific and undetermined circumstances. Cortex, 69, 265-278. doi: 10.1016/j.cortex.2015.04.014

Peterson, M. A., \& Gibson, B. S. (1991). Directing spatial attention within an object: Altering the functional equivalence of shape descriptions. Journal of Experimental Psychology: Human Perception and Performance, 17, 170-182. doi: 10.1037/00961523.17.1.170

Poarch, G. J., \& van Hell, J. G. (2012). Executive functions and inhibitory control in multilingual children: Evidence from second-language learners, bilinguals, and trilinguals. Journal of Experimental Child Psychology, 113, 535-551. doi: 10.1016/j.jecp.2012.06.013

Ross, J., \& Melinger, A. (2016). Bilingual advantage, bidialectal advantage or neither? Comparing performance across three tests of executive function in middle childhood. Developmental Science, 1-21. doi: 10.1111/desc.12405 
Scocchia, L., Valsecchi, M., \& Triesch, J. (2014). Top-down influences on ambiguous perception: The role of stable and transient states of the observer. Frontiers in Human Neuroscience, 8. doi: 10.3389/fnhum.2014.00979

Sorge, G. B., Toplak, M. E., Bialystok, E. (2017). Interactions between levels of attention ability and levels of bilingualism in children's executive functioning. Developmental Science, 20. doi: 10.1111/desc. 12408

Wimmer, H., \& Perner, J. (1983). Beliefs about beliefs: Representation and constraining function of wrong beliefs in young children's understanding of deception. Cognition, 13, 103-128. doi: 10.1016/0010-0277(83)90004-5

Wimmer, M. C., \& Doherty, M. J. (2007). Investigating children's eye-movements: Cause or effect of reversing ambiguous figures? 29th Annual Cognitive Science Society, 1659 1664.

Wimmer, M. C., \& Doherty, M. J. (2010). Children with autism's perception and understanding of ambiguous figures: Evidence for pictorial metarepresentation, a research note. British Journal of Developmental Psychology, 28, 627-641. doi: $10.1348 / 026151009 X 465362$

Wimmer, M. C., \& Doherty, M. J. (2011). The development of ambiguous figure perception. Monographs of the Society for Research in Child Development, 76 (1), 1-130. doi: $10.1111 / \mathrm{j} .1540-5834.2011 .00590 . \mathrm{x}$

Wimmer, M. C., \& Marx, C. (2014). Inhibitory processes in visual perception: A bilingual advantage. Journal of Experimental Child Psychology, 126, 412-419. doi:

10.1016/j.jecp.2014.03.004 
Table 1. Summary of mean performance on ambiguous figures production, reversal, false belief, and Droodle tasks and average British Picture Vocabulary Scale (BPVS-III) raw score for monolinguals and bilinguals (standard deviation in parenthesis).

\begin{tabular}{lllllll}
\hline & Production & Reversal & False Belief & Droodle & BPVS-III \\
& (range 0-3) & (range 0-3) & (range 0-1) & (range 0-1) & \\
\hline $3-4$ years & & & & & \\
Monolinguals & $1.00(.84)$ & $.06(.24)$ & $.22(.43)$ & $.06(.24)$ & 33.22 \\
$(N=18)$ & & & & & & \\
Bilinguals & $1.73(1.33)$ & $.67(.98)$ & $.27(.46)$ & $.13(.35)$ & 34.87 \\
$(N=15)$ & & & & & & $(16.71)$ \\
5 years & & & & & & \\
Monolinguals & $2.69(.60)$ & $1.06(.85)$ & $.81(.40)$ & $.69(.48)$ & 71.06 \\
$(N=16)$ & & & & & & $(12.48)$ \\
Bilinguals & $2.83(.38)$ & $1.72(1.07)$ & $.72(.46)$ & $.67(.48)$ & 72.11 \\
$(N=18)$ & & & & & & $(12.07)$ \\
\hline
\end{tabular}


Table 2. Linear regression results on production performance (mean number of alternative interpretations produced) using backwards elimination.

B $\quad$ SE b $\quad B$

\begin{tabular}{|c|c|c|c|c|}
\hline Produc & & & & \\
\hline Step 1 & Constant & -.57 & .25 & \\
\hline & Language group & .11 & .06 & .14 \\
\hline & Age & .01 & .006 & $.36^{*}$ \\
\hline & BPVS-III & .007 & .003 & $.45 * *$ \\
\hline & Droodle & -.04 & .09 & -.06 \\
\hline & False Belief & -.01 & .08 & -.001 \\
\hline Step 2 & Constant & -.57 & .25 & \\
\hline & Language group & .11 & .06 & .14 \\
\hline & Age & .01 & .006 & $.36^{*}$ \\
\hline & BPVS-III & .007 & .003 & $.45 * *$ \\
\hline & Droodle & -.05 & .08 & -.06 \\
\hline Step 3 & Constant & -.52 & .23 & \\
\hline & Language group & .11 & .06 & .14 \\
\hline & Age & .01 & .006 & $.33 *$ \\
\hline
\end{tabular}

Note. $\mathrm{R}^{2}=.60$ for Step 1: $\Delta \mathrm{R}^{2}=.0$ for Step $2(p>.05): \Delta \mathrm{R}^{2}=-.002$ for Step $3(p>.05) . * p<$ $.05, * * p<.01, * * * p<.001$. 
Table 3. Linear regression results on reversal performance (mean number of figures reversed) using backwards elimination.

B

Reversal

Step 1

$-.97$

.32

Language group .22

.02

.08

$.31^{* *}$

Age

$-.001$

.008

$.45^{*}$

BPVS-III

.10

.003

$-.06$

Droodle

.01

.11

.14

False Belief

.10

.008

\section{Step 2}

Constant

$-.97$

.32

Language group $\quad .22$

.08

$.31 * *$

Age

.02

.008

$.45^{*}$

BPVS-III

$-.001$

.003

$-.06$

Droodle

.10

.10

.14

\begin{tabular}{lllll}
\hline Step 3 & Constant & -.92 & .28 & \\
& Language group & .22 & .08 & $.31^{* *}$ \\
& Age & .02 & .005 & $.40^{* *}$ \\
& Droodle & .10 & .10 & .14 \\
\hline Step 4 & Constant & -1.06 & .24 & $.30^{* *}$ \\
& Language group & .22 & .08 & $.49^{* * *}$
\end{tabular}

Note. $\mathrm{R}^{2}=.40$ for Step 1: $\Delta \mathrm{R}^{2}=.004$ for Step $2(p>.05): \Delta \mathrm{R}^{2}=-.001$ for Step $3(p$ $>.05): \Delta \mathrm{R}^{2}=-.01$ for Step $4(p>.05) .{ }^{*} p<.05, * * p<.01, * * * p<.001$. 
Table 4. Summary of BPVS performance, Droodle and False Belief (standard deviation in parentheses) comparing mono- and bilinguals. Mean differences and effect size after controlling for age, with 95\% CI.

\begin{tabular}{llll}
\hline & BPVS & $\begin{array}{l}\text { Droodle } \\
\text { (range 0-1) }\end{array}$ & $\begin{array}{l}\text { False Belief } \\
\text { (range 0-1) }\end{array}$ \\
\hline Monolinguals & $54.4(22.9)$ & $0.41(0.50)$ & $0.48(0.51)$ \\
Bilinguals & $59.3(21.9)$ & $0.52(0.51)$ & $0.59(0.50)$ \\
Difference & $-3.1[-8.8,2.5]$ & $0.026[-0.16,0.22]$ & $-0.09[-0.28,0.11]$ \\
Effect size (r) & $-.13[-.36, .11]$ & $.03[-.21, .27]$ & $-.10[-.33,0.14]$ \\
\hline
\end{tabular}


Table 5. Summary of mean performance on ambiguous figures production, proportion of figures reversed and total number of reversals (standard deviation in parentheses, $95 \% \mathrm{CI}$ in square brackets). Mean differences after controlling for age, with 95\% CI.

\begin{tabular}{llll}
\hline & $\begin{array}{l}\text { Production } \\
(\text { range 0-3) }\end{array}$ & $\begin{array}{l}\text { Number reversed } \\
(\text { range 0-3) }\end{array}$ & $\begin{array}{l}\text { Total reversals } \\
\text { (range 0-9) }\end{array}$ \\
\hline Monolinguals & $1.79(1.12)[1.41,2.18]$ & $.53(.79)[0.29,0.82]$ & $2.41(1.76)[1.85$, \\
Bilinguals & $2.33(1.08)[1.94,2.67]$ & $.1 .24(1.15)[0.85,1.61]$ & $3.03(2.28)[2.24$, \\
& & & $3.82]$ \\
Difference & $0.25[-0.130 .60]$ & $0.63[0.19,1.07]$ & $0.30[-0.621 .17]$ \\
\hline
\end{tabular}




\section{Figure Captions}

Figure 1. Mode of first reversal time across the three figures as a function of language group. Figure 2. Standardised effect sizes, with 95\% CI. AFP = Ambiguous Figure Production task, Reverser $=$ number of figures reversed, Tot $\operatorname{Rev}=$ total number of reversals, for those who reversed at all. 
Figure 1.

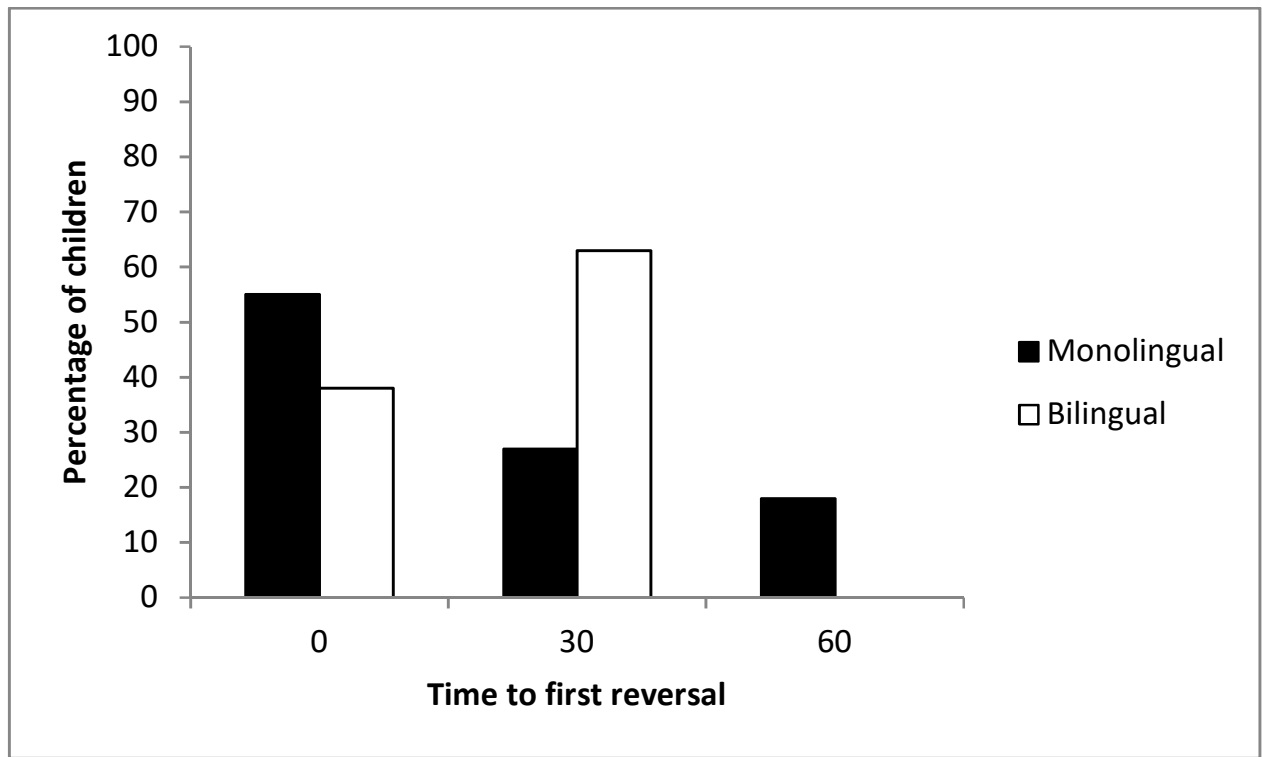


Figure 2.

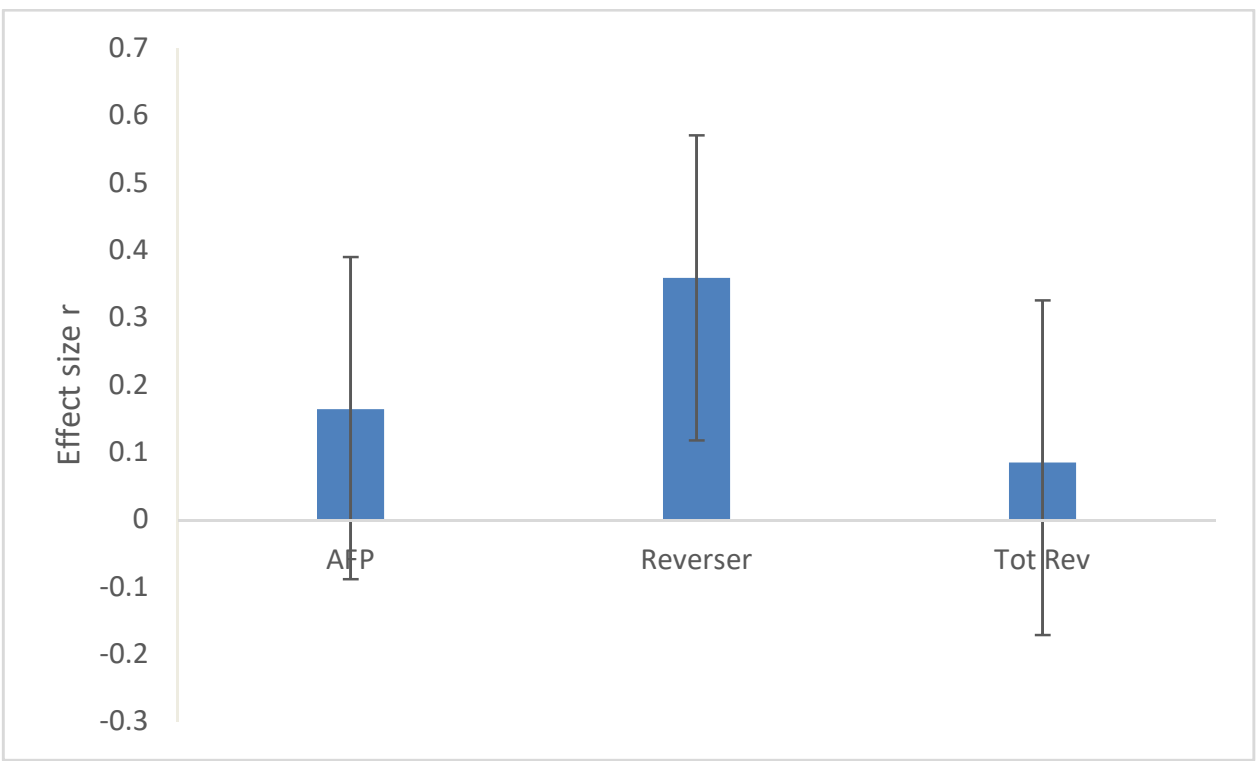

